\title{
O CONSUMO DE MODA E A CONSTRUÇÃO DE IDENTIDADE DO ADOLESCENTE
}

\author{
The consumption of fashion and the construction of identity of the adolescent
}

TOSTES, Francyelle Ribeiro

Universidade Estadual de Londrina

fran_tostes@hotmail.com

SANCHES, Maria Celeste de Fátima

Universidade Estadual de Londrina

tsanches@sercomtel.com.br

\section{Resumo}

O artigo teve como propósito investigar a influência do consumo de moda na construção de identidade, no período da adolescência. Para isso, foi realizada uma revisão bibliográfica, uma análise de imagens publicitárias e a aplicação de um questionário de cunho qualitativo. Assim, verificou-se a influência do consumo de moda nesse processo, contribuindo para compor e expressar a personalidade do jovem. Porém, constatou-se que algumas estratégias utilizadas pelo marketing de moda adolescente, podem ser nocivas e causar problemas na aceitação da auto-imagem.

Palavras-chave: consumo de moda; construção de identidade; auto-imagem; marketing.

\section{Abstract}

The purpose of this article was to investigate the influence of fashion consumption on the identity construction, during adolescence. For this, a literature review, an analysis of advertising images and a qualitative survey was conducted. This way, we verified the positivity of fashion consumption in this process, as a tool to compose and express the personality of the adolescent. However it was found that the strategies used by the fashion marketing to young people, can be harmful and cause problems in the acceptance of self-image.

Keywords: fashion consumption; identity construction; self-image; marketing. 


\section{INTRODUC̣ÃO}

Ao pensarmos no papel social da moda é preciso ter uma visão global do que ela representa, uma visão que vá além da ideia de consumo e publicidade. Moda é um fenômeno social e histórico e deve ser abordada em toda sua complexidade, contemplando diferentes áreas do saber.

Sob a abordagem da psicologia sócio-histórica, a moda é vista como um processo em movimento que se dá dentro e fora do indivíduo. Dessa forma, nas relações que se desenvolvem no universo da moda, o indivíduo é parte ativa do processo, contribuindo para sua transformação constante e sendo influenciado por ele. Assim, a moda se consuma no corpo, modifica-se para se adequar ao corpo, e o corpo modifica-se para adequar-se à moda.

Por isso, estudar o fluxo da moda pode ser útil para a compreensão da formação da personalidade, já que a sua influência sobre o sujeito abrange as noções de identidade, pertencimento e diferenciação. De acordo com Embacher (1999), ao construir seu próprio estilo, o indivíduo torna-se representante de si mesmo e cria uma identidade que articula suas igualdades e diferenças em relação ao contexto onde está inserido ao longo de sua história.

Isso acontece, ainda segundo Embacher (1999), devido a relação entre a necessidade de adequar seus papéis sociais e a capacidade de pautar sua identidade pelo próprio desejo. Esse processo inicia-se na infância, quando a identidade do indivíduo e o grupo social em que está inserido são pressupostos pelos pais. Embora as escolhas, inclusive as que dizem respeito ao vestuário, sejam guiadas pela família no início da vida, percebe-se que a expressão pessoal e a articulação de trocas sociais é, na maior parte do tempo, mediada pelo uso de artefatos.

Quando pensamos no uso de objetos como forma de interação social, devemos retornar aos primórdios da história. De acordo com Ehrenberg (2012), nas sociedades primitivas, o consumo tinha como finalidade somente atender as necessidades fisiológicas, como fome, frio e abrigo. Já na era medieval o ato de consumir passa a representar também a diferenciação social, pois diferentemente dos camponeses, a nobreza podia consumir roupas, jóias e até pessoas (escravos) por vaidade e desejo, sendo o primeiro indício dessa diferenciação. Assim, a relação estabelecida entre sujeito e objeto sempre contribuiu para identificar as práticas sociais e culturais dos indivíduos.

Neste sentido, Miranda (2008) afirma que os objetos acabam tornando-se sistemas de informações, pois reproduzem mensagens, além de estabelecerem 1 Nesse caso, o termo refere-se à utilização de artefatos e consumo de alimentos, não à produção capitalista de mercadorias.

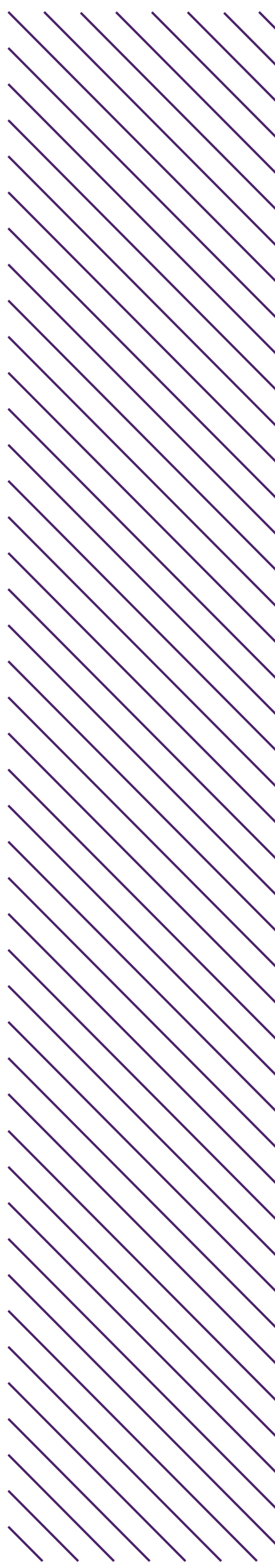


posições hierárquicas na sociedade, uma vez que, através deles, sabemos quem tem melhor situação econômica, quem tem nível intelectual mais elevado e etc. Na sociedade pós-moderna, o indivíduo acredita ser e espera trasmitir aos outros a imagem que cria através do consumo desses objetos, mesmo que muitas vezes essa imagem não corresponda à realidade. De acordo com Baudrillard (1991), o consumidor se molda em um mundo imaginário onde as imagens importam mais do que a realidade.

Nesse contexto, a moda tem grande relevância para construção da identidade social, visto que seus produtos desempenham um papel no âmbito público e no privado, pois possibilitam a criação de uma imagem apresentada socialmente, assim como compõem, no imaginário do indivíduo, o papel que ele deseja representar.

Por conseguinte, uma vez que estudamos o consumo simbólico, é necessário analisar os fatores que fazem o indivíduo vestir-se de determinada forma e as motivações que o levam a comprar ou não certos produtos. Tais aspectos podem ter origens tanto internas (auto-estima, relações familiares, necessidade de pertencer a algum grupo), como externas (apelo midiático, publicidade, ambiente social). Contudo, esses fatores podem agir com mais força em indivíduos que ainda encontram-se em uma etapa caótica da formação de identidade, como é o caso dos adolescentes.

Segundo Knobel (1981) a adolescência é marcada por desequilíbrios e instabilidades extremas, o que ele denomina de "síndrome normal da adolescência" - uma entidade semipatológica. Essa síndrome, que faz parte do processo de desenvolvimento de identidade, é marcada por turbulências resultantes do luto pelo corpo e identidade infantis, dos quais o adolescente tem que se desfazer, assim como do luto pela perda da imagem de total proteção dos pais da infância.

Nessa conflituosa fase de questionamentos e inseguranças, a roupa irá representar um fator muito importante na construção da identidade. As alterações na forma de vestir-se serão os primeiros indicadores de mudanças, representando o grupo social ao qual o adolescente deseja pertencer e a imagem que visa apresentar socialmente.

Diante dessa perspectiva, o presente artigo tem como objetivo analisar a influência do consumo de moda no processo de desenvolvimento da identidade dos adolescentes (jovens entre 12 e 18 anos), observando que fatores se destacam nesta relação. Essa influência será avaliada através por uma pesquisa exploratória, investigando a visão dos jovens a respeito do próprio consumo de moda, assim como pela identificação das estratégias utilizadas pelo marketing de moda para atingir esse público, por meio de uma análise de imagens 
publicitárias. A partir de tal verificação, buscamos examinar a ação positiva e/ou negativa do consumo de moda sobre esta etapa do desenvolvimento humano, para então discutir alternativas para aquelas consideradas nocivas ao processo de formação de identidade dos jovens.

\section{METODOLOGIA}

Inicialmente fizemos um levantamento bibliográfico para um aprofundamento no tema proposto, procurando entender como ocorre o consumo simbólico e quais as particularidades e hábitos de consumo dos adolescentes - jovens de 12 a 18 anos. Procuramos também, através da revisão bibliográfica, levantar informações a respeito das estratégias de marketing utilizadas para atingir esse público. Para a visualização de tais estratégias, efetuamos uma análise de imagens publicitárias direcionadas aos jovens. As imagens foram analisadas procurando evidenciar os conteúdos visuais e textuais implícitos que pudessem estar relacionados à questões de imagem corporal, à exclusividade e às estratégias de aproximação ao público adolescente.

Posteriormente, conduzimos uma pesquisa de campo, articulada através de um questionário padronizado de cunho qualitativo. A pesquisa qualitativa tem como objetivo produzir informações aprofundadas e ilustrativas, independentemente do tamanho da amostra, importando-se apenas em produzir novas informações (DESLAURIERS, 1991 apud GERHARDT e SILVEIRA, 2009).

O questionário, contento 19 questões, foi aplicado online em grupos de redes sociais que reuniam jovens de 12 a 18 anos, no período de 21 de julho de 2014 a 28 de agosto de 2014 . O objetivo da pesquisa foi levantar informações a respeito da imagem que o adolescente tem sobre seus hábitos de consumo, bem como identificar de que forma esses jovens recebem as estratégias de marketing utilizadas nas companhas publicitárias de moda. Procuramos também, coletar dados a respeito das possíveis influências que essas campanhas podem ter na composição da auto-imagem do adolescente, bem como na sua identidade em formação.

\section{REVISÃO BIBLIOGRÁFICA}

\section{O consumo de moda na adolescência:}

De acordo com Ariès (1981), até ao século XVIII a adolescência era

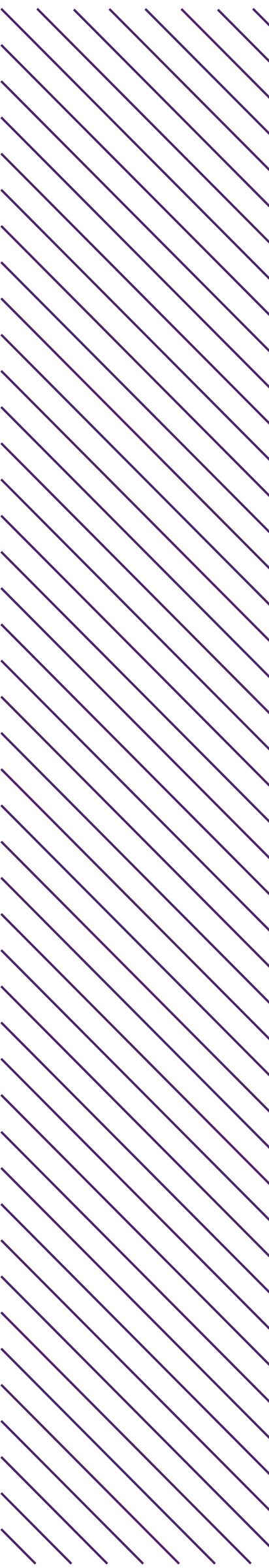


confundida com a infância, porém a partir do século XIX, o conceito de adolescência começa a aproximar-se do utilizado atualmente.

O primeiro adolescente moderno típico foi o Siegfried de Wagner: a música de Siegfried pela primeira vez exprimiu a mistura de pureza (provisória), de força fisica, de naturismo, de espontaneidade e de alegria de viver que faria do adolescente o herói do nosso século XX, o século da adolescência. Esse fenômeno, surgido na Alemanha wagneriana, penetraria mais tarde na França, em torno dos anos 1900. A "juventude", que então era a adolescência, iria tornar-se um tema literário e uma preocupação dos moralistas e dos políticos. Começou-se a desejar saber seriamente o que pensava a juventude, e surgiram pesquisas sobre ela, como as de Massis ou de Henriot. A juventude apareceu como depositária de valores novos, capazes de reavivar uma sociedade velha e esclerosada (ARIÈS, 1981: 46).

Para Cano et al. (1999), na busca por decifrar a adolescência, o tema têm sido, até a atualidade, alvo de várias pesquisas, sendo compreendida como um período de grande relevância no processo de desenvolvimento humano. Esse período é marcado por transformações físicas e biológicas, associadas a mudanças psicológicas e sociais que resultarão posteriormente em um indivíduo adulto.

Ainda segundo Cano et al. (1999), entre essas transformações, a mudança corporal causa grande impacto na formação de identidade do adolescente, tendo em vista que sua identidade está sempre vinculada às identificações: inicialmente com os pais e posteriormente com grupos da mesma idade. Nesse processo de identificação, a imagem corporal é extremamente importante, pois é através dela que o jovem se sente aceito ou não socialmente, comparando-se com outros adolescentes ou com estereótipos de beleza veiculados pela mídia.

Durante o período da adolescência os jovens recebem influências de todos os lados: dos amigos, dos pais, da televisão, da publicidade. Na sociedade atual, o grande apelo que sofrem, não só os jovens, mas também adultos e até crianças, é de uma imagem perfeita, como afirma Pereira (2010). Existe nos dias de hoje, uma cobrança da socieadade para que sejamos bonitos, magros, musculosos e sigamos tendências de moda.

Neste contexto, o capitalismo vê as crianças e os adolescentes como seus clientes preferenciais, e a indústria da moda tem seus produtos direcionados para esses jovens. Segundo Moura (2013) desde criança o indivíduo já aprende, observando o exemplo dos pais, que consumir gera prazer.

De acordo com a matéria de Portugal (2013), "As marcas preferidas das mulheres da geração $Y^{\prime \prime}$, o grupo financeiro multinacional Goldman Sanchs 
realizou uma parceria com a revista TeenVogue para elencar quais seriam as 50 marcas mais apreciadas pela geração $Y$ (jovens nascidos entre 1980 e anos 2000). De acordo com a pesquisa, eles superarão a geração Boomers no consumo de artigos de vestuário nos próximos 5 anos, aumentando esse consumo de $20 \%$ a $25 \%$ (PORTUGAL, 2013).

Por outro lado, para a analista do Goldman Sanchs, Lindsay Drucker, essa geração teria menor inclinação a cartões de crédito e menor apoio financeiro, portanto, não pretendendo acumular dívidas e com menos dinheiro, eles se tornarão mais exigentes, fazendo com que as marcas invistam mais em produtos e publicidade.

Entre os adolescentes consumidores de moda, encontram-se perfis diferenciados de grupos (BENEDETTI; NICOLETTI, 2010), como por exemplo, jovens que seguem tendências de moda religiosamente. Eles querem usar o que surge de novo, desejam roupas de marca e consomem artigos de moda várias vezes ao ano. Já outros preferem uma moda personalizada, gostam de customizar a própria roupa. Com um sentimento de individualização evidente, esses jovens querem consumir produtos de moda, porém desejam sentir-se únicos.

Existem também os adolescentes que consomem artigos de moda mais acessíveis e procuram por produtos em promoção. Eles avaliam mais o produto antes da compra e são pessoas com uma situação enconômica geralmente não muito elevada, o que os leva a consumir produtos de moda mais básicos.

É evidente na realidade atual, que o consumo de moda dos adolescentes sofre forte influência da mídia, da cultura pop e dos grupos em que eles se inserem (PEREIRA, 2010). Mas esse consumo também é pautado pela necessidade dos jovens de buscar o novo, na tentativa de estabelecer um identidade própria através dos produtos consumidos (BAUDRILLARD, 2010).

\section{A moda e suas contribuições na formação de identidade:}

No processo de formação de identidade, a auto-imagem desempenha um papel de grande importância. A constituição de uma imagem corporal contempla as formas como o indivíduo conceitua seu corpo, sendo esta o reflexo da forma como ele se relaciona com o mundo. É através dessa relação com o ambiente que ele se conhece e desenvolve uma identidade (TOSATTI; PERES; PREISSLER, 2007).

No decorrer da construção constante dessa identidade própria, a imagem que apresentamos à sociedade está estritamente relacionada à moda 
(MIRANDA, 2008), já que através dela podemos adotar um estilo, que é a nossa essência traduzida em nossa forma de vestir. A moda nos proporciona ferramentas de manipulação da nossa imagem, para torná-la a representação da nossa individualidade e compormos o nosso estilo pessoal. Segundo Embacher (1999), na modernidade o individualismo surge como uma ideologia, fazendo com que o indivíduo não só tenha o direito, mas também o temor de não sustentar essa autonomia.

Assim, na busca incessante para nos estabelecermos como indivíduos, a apropriação dos valores simbólicos dos objetos (nesse caso, de vestuário) tem grande relevância. O consumo, nesse processo, nos aproxima e distancia do que queremos ter ou nos tornar, já que está em constante mudança de padrões.

O valor simbólico do que consumimos é o que expressa a nossa identidade. Esses objetos e serviços consumidos são o que materializam a nossa tentativa de ser de uma determinada forma e representar determinado papel social (GIDDENS, 2002).

Na sociedade atual, o indivíduo acaba tendo que representar papéis diversos, e a moda contribui de forma muito relevante para isso (CASTRO e ALMEIDA, 2011), pois para cada ocasião e âmbito de nossas vidas, encontramos uma forma de vestir apropriada. Não só o consumo de moda, mas o consumo de uma forma geral, está ligado a projeção que fazemos de nossas identidades nos objetos. Por conseguinte, não somos o que compramos, mas compramos o que somos ou gostaríamos de ser (MIRANDA, 2008).

De acordo com a etapa evolutiva da vida em que encontra-se e ao longo dela, o consumidor terá características distintas. Dessa forma, a idade do indivíduo exerce grande influência em sua forma de consumir (SOLOMON, 2006).

No setor de vestuário, segundo Pandjiarjian (2008), os adolescentes são o segundo público que mais consome artigos de moda - perdendo apenas para o público feminino - além de possuirem um grande conhecimento de marcas.

No entanto, a influência de algumas marcas de moda pode se negativa nesse processo de construção de identidade dos jovens, por criarem uma autoimagem distorcida ao corroborarem padrões de beleza que, na maioria das vezes, são idealizados e não correspondem a realidade. Dessa modo, acabam restringindo o consumo de seus produtos a jovens que estejam dentro desses padrões.

A marca de vestuário americana Abercrombie \& Fitch, no ano passado anunciou que não faria mais roupas femininas no tamanho $G$ e $G G$, alegando 
que não tinha interesse em associar a marca à esse tipo de público. De acordo com a matéria do site InfoMoney de maio/2013, a linha masculina ainda contaria com esses tamanhos para atender aos jovens atletas, como os jogadores de futebol americano (VERONESI, 2013).

Com uma iniciativa como essa, a marca que tem como público alvo os jovens, acaba por excluir abertamente adolescentes consideradas "acima do peso", na visão da empresa. Os impactos que isso pode ter em uma jovem que utiliza esse manequim e não pode mais consumir os produtos da marca, podem abalar profundamente sua autoestima, em uma fase que lidar com a autoimagem é uma tarefa um tanto quanto turbulenta.

De acordo com Heinzelmann e Strey (2010) a mídia exerce papel fundamental na divulgação de uma sociedade da lipofobia em que a gordura é nociva a beleza. Para a autora, esses valores são transmitidos desde cedo para as meninas através de revistas para adolescentes, como a Capricho, sendo reforçados em publicações para público adulto, como a Vogue.

Um modelo de mulher ideal é proposto pela mídia e pela moda através de campanhas publicitárias, revistas e etc., as quais nos reforçam que devemos estar de acordo com esse modelo, não explícitamente mas de forma muito persuasiva, repetindo sempre o mesmo biotipo padrão em suas publicações. Essas campanhas publicitárias e revistas excluem a existência de outros corpos, que não são considerados uma opção estética viável (HEINZELMANN e STREY, 2010).

Os indivíduos que habitam esses corpos excluídos, que fogem de um padrão estético vigente, acabam tornando-se mais propensos à doenças psíquicas como anorexia, bulimia e vigorexia. Além dessas doenças, a publicidade e o julgamento estético que ela propõe, estimulam a procura por intervenções cirúrgicas estéticas em adolescentes que buscam um corpo perfeito, em uma fase que seus corpos ainda está em constante mudança.

Uma ferramenta muito utilizada em campanhas publicitárias é a manipulação digital de imagens. Na maioria das vezes essas manipulações, utilizando-se de softwares como o Photshop, tem o objetivo de remover imperfeições dos corpos e rostos dos modelos. Essas alterações tem a intenção de vender para os jovens, assim como para outros públicos-alvos, a existência de pessoas fisicamente perfeitas. Logo, através desse recurso, essas campanhas vendem um corpo (ou um produto) que não é real e os efeitos em adolescentes, que encontram-se em uma fase conturbada de vunerabilidade e de inseguranças em relação a auto-imagem, tem uma amplitude maior e são quase sempre negativos. 


\section{Marketing de moda para adolescentes:}

O marketing, segundo Burrowes (2005), é a técnica de criar, disputar, ocupar e preservar nichos do mercado, estando presente desde a concepção do produto, orientando também sua produção.

No Brasil, os adolescentes movimentam bilhões de dólares anualmente em produtos pessoais e são alvos de infinitas pesquisas de marketing (GADE, 1998). As propagandas tentam seduzir os jovens a consumirem exageradamente, cultuando a estética e ditando tendências a serem seguidas.

Para Schiffman e Kanuk (2000), os adolescentes tornaram-se alvo dos profissionais de marketing pelo grande poder que exercem na dinâmica de consumo da família - já que são ainda dependentes economicamente dos pais além de representarem os consumidores independentes em um futuro próximo.

Dessa forma, o marketing de moda para adolescentes tenta utilizar ao máximo seu poder de persuasão para conquistar essa parcela de consumidores tão importantes, além de aproveitar-se da grande receptividade com que essa faixa etária recebe influências midiáticas.

Provando quão agressivo esse marketing pode ser, de acordo com a matéria "Forever 21 asked about maternity line" publicada no site do canal de notícias norte-americano CNN, a loja de departamentos Forever 21 criou em 2010, uma linha de roupas para jovens gestantes, a "Love 21 Maternity", que foi comercializada apenas em estados dos E.U.A. com altos índices de gravidez na adolescência.

No entanto, a marca não confirmou que a escolha de tais estados para a venda da linha de roupas tenha sido uma estratégia de marketing. De qualquer forma, nota-se o esforço da empresa para conquistar um sub-grupo de consumidores muito específico dentro do universo adolescente.

Um outro exemplo de estratégia visando atingir o público jovem é a utilização de redes sociais. Além do uso de sites populares na atualidade, como Facebook, Instagram e Twitter - que já estão sobrecarregados de anúncios e perfis de marcas jovens tentando aproximar-se de seu público-alvo - um novo aplicativo onde as pessoas enviam fotos e vídeos que são deletados automaticamente após alguns segundos, o Snapchat, também vem sendo utilizado como ferramenta de marketing digital.

Segundo a matéria de dez./2013 do site do jornal Folha de S. Paulo, febre entre os adolescentes, esse aplicativo permite que as marcas entrem em contato com os jovens, mas somente através de solicitação de amizade, criando dessa 
forma, um clima mais intimista entre a empresa e o consumidor. Através do Snapchat as marcas criam promoções relâmpago a curto prazo, aproveitando o apelo de imediatismo do aplicativo, além de disponibilizarem cupons de desconto (que desaparecem depois de alguns segundos, dentro da proposta do aplicativo). Criam também competições, em que vence quem responder mais rápido as mensagens da empresa, além de receberem sugestões e opiniões dos clientes de uma forma mais pessoal. "Os profissionais de marketing vêem os adolescentes como 'consumidores em treinamento', pois a lealdade à marca, com frequência, se desenvolve durante a adolescência." (SOLOMON, 2006 p. 357).

Essa postura agressiva do marketing, talvez seja resultante dessa visão do jovem como consumidor em treinamento, ou então consequência da postura do próprio adolescente que, na maioria das vezes, consome sem se preocupar em exercer um consumo consciente. Assim, o mercado de moda e a mídia encontraram no adolescente um terreno fértil para o lançamento de novos produtos, novas tendências, tudo sempre explorando o conceito do novo, do passageiro.

É importante porém, ressaltar que esse perfil de consumidor não é uma característica intrínseca à adolescencia. Para Ribeiro (2005), a postura do consumidor adolescente atual é fruto da sociedade consumista em que vivemos, onde o sistema capitalista visa o público jovem como alvo central.

Entre as estratégias do marketing, destaca-se a publicidade que, segundo Souza (2000), alterou seu objetivo com o tempo. Nos dias de hoje, além de vender produtos e serviços, ela também cria modelos a serem seguidos, transmitindo valores sociais e pessoais e apresentando padrões físicos, estéticos e comportamentais, aos quais os indivíduos devem moldar-se.

Dentro do ambiente do marketing a publicidade está inserida no "composto de comunicação":

A publicidade faz parte do que se chama "composto de comunicação", que inclui também a logística, a distribuição e a venda pessoal. Este "composto de comunicação", junto com o "composto de apresentação", cujos elementos são design, marca, embalagem, preço e assistência ao consumidor formam o chamado "composto de marketing" ou "marketing mix". (BURROWES, 2005. p. 207)

O propósito central da publicidade é agir sobre as emoções e interesses do público, criando o desejo e motivando a ação para o consumo do produto. Ela é uma ferramenta de persuasão que mobiliza a necessidade real ou imaginária

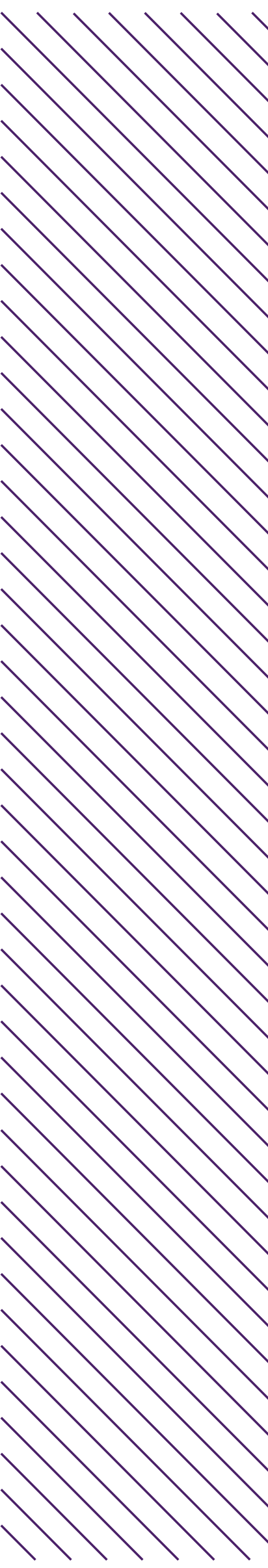


do indivíduo, através de estratégias que transformem o desejo do consumo em necessidade a ser suprida, associando o produto à obtenção de bens simbólicos ou status social. No entanto, essas estratégias de conquista, hoje em dia, tem dedicado-se mais a "fazer crer", do que a possibilitar um consumo consciente e informado. A publicidade tem se ocupado em captar sonhos e aspirações para apresentá-los ao público em forma de produtos (NASSIF, 2009).

Em nosso cotidiano nos deparamos a todo momento com imagens publicitárias e, conforme Cunha (2005), uma análise mais profunda dessas imagens, revela a existência de elementos de grande importância, construídos de forma a interferir nas relações do indivíduo consigo próprio e com as pessoas ao seu redor.

Utilizando-se de idealizações existentes no imaginário coletivo, as campanhas publicitárias atingem mais profundamente grupos mais vulneráveis, como adolescentes de classes econômicas mais baixas. De acordo com Oliveira (2009), uma pesquisa realizada sobre roubo de peças de vestuário na década de 1980 na Europa, constatou que para os jovens, possuir determinadas roupas enaltecidas em campanhas publicitárias, seria como pertencer ao mundo dos eleitos. Então, quando os pais não tinham condições de proporcionar-lhes o consumo dessas roupas, esses jovens hostilizavam outros nas saídas de colégios de classe alta. Os jovens que não consumiam tais produtos sentiam-se frustrados e excluídos pela sociedade.

Assim, como estratégia de marketing podemos apontar a "exclusividade" ou a "exclusão". O que torna o produto sedutor é ser acessível a poucos, seleção que se dá pelo valor alto de artigos de luxo, como também pela restrição da numeração dos manequins a tamanhos pequenos (excluindo pessoas que não sejam magras, como os modelos que aparecem nas campanhas publicitárias). Nas palavras do CEO da Abercrombie \& Fitch, marca de grande sucesso entre os jovens de classe alta, Mike Jeffries: "Você não exclue ninguém, mas também não empolga ninguém."

\section{Análise de imagens publicitárias - Abercrombie \& fitch:}

De acordo com Souza e Custódio (2005), a importância das campanhas publicitárias no campo da moda entrou em voga nos anos 90 , quando garantir a qualidade do produto não era mais suficiente, e a representação da identidade da marca tornou-se necessário. Assim, através da imagem iniciou-se a exploração dos elementos de identidade da marca.

As imagens publicitárias sofrem manipulação em seus conteúdos, para que nem sempre se perceba qual é o direcionamento emocional que elas 
pretendem causar em seu público alvo. Essas imagens, em sua maioria, utilizamse da "manipulação de desejos" para ir de encontro as necessidades internas do receptor e levar a compra do produto (SOUZA; CUSTÓDIO, 2005).

Ao analisarmos uma imagem publicitária, devemos levar em conta os signos representantes do imaginário social nela contidos. Para tal análise podemos utilizar os conceitos de uma das estratégias do marketing de moda, a exclusão, já que nas imagens analisadas neste estudo fica evidente a escolha de um tipo físico predominante, considerado pela marca com o ideal. Partindo-se dessa ideia de exclusividade, analisaremos os conteúdos semânticos implícitos nas imagens.

As imagens a seguir pertencem a campanhas publicitárias da marca Abercrombie \& Fitch; a escolha de tal marca ocorreu por seu público-alvo ser composto por adolescentes e universitários, além de sua associação a um estilo de vida em que o culto ao corpo é fator determinante.

Através de várias declarações polêmicas, o CEO da marca Abercrombie \& Fitch, Michael Jeffries já deixou claro que seu público-alvo são jovens bonitos, magros e "descolados". E o sentido de "descolados" ao qual ele se refere está totalmente relacionado à aparência física, não importando ideias, caráter ou moral. Estar acima do peso ou ter uma aparência física fora dos padrões socialmente estabelecidos, torna qualquer indivíduo em alguém "não descolado". Grande parte das campanhas publicitárias da marca, apresentam jovens com corpos definidos em poses sensuais, dando as imagens um teor sexual implícito e explícito.

Analisaremos então as imagens seguintes, relacionando seus conteúdos visuais às mensagens nelas implícitas, levando em conta também os conteúdos textuais nelas presentes. As imagens selecionadas apresentam figuras centrais masculina e feminina na intenção de ressaltar que ambos os sexos são alvos das campanhas publicitárias da marca em questão.

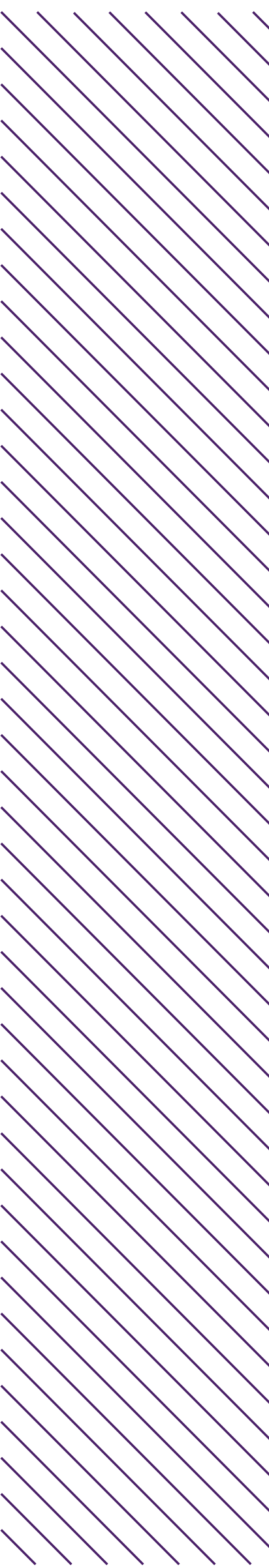




\section{Figura 1 - Imagem da campanha Verão/2011}

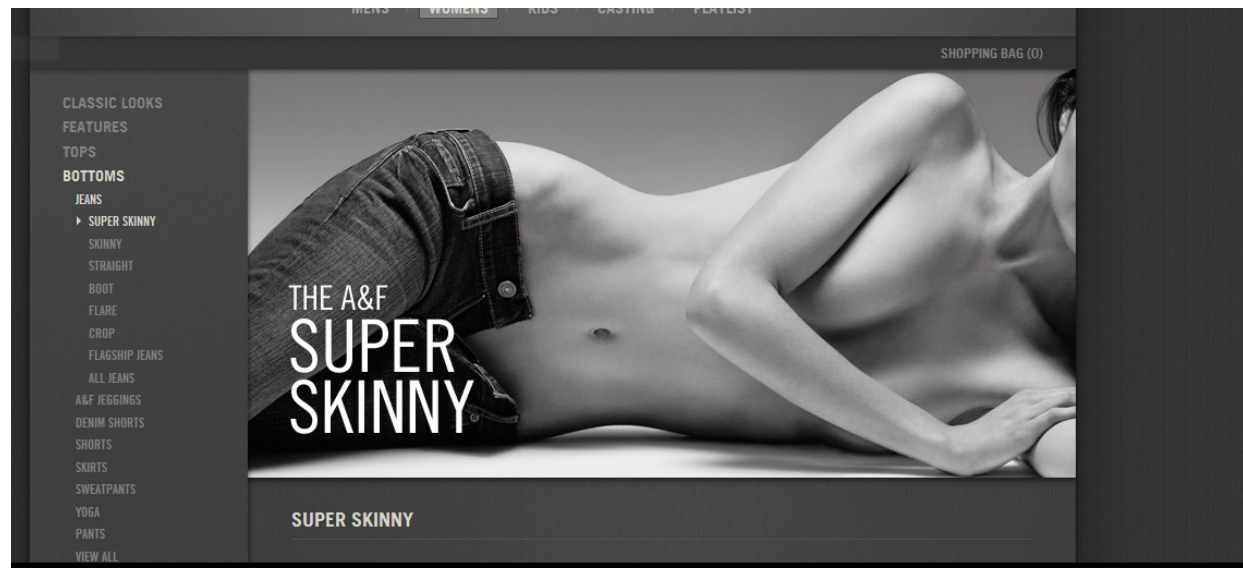

Fonte: Website Kailee H, fevereiro de 2011

Na imagem anterior, que estava publicada no website da marca, além do apelo sexual explicitado pela nudez da modelo, é possível entender a duplicidade da mensagem "super skinny" (traduzida para o português como "super magro") que além de referir-se ao corte da calça jeans que é bem justo, remete também a ideia de que a pessoa que usar a calça deve ser muito magra, e assim, fisicamente atraente. A modelo da foto é uma pessoa magra e a imagem provavelmente foi retocada digitalmente para dar a impressão de um corpo sem imperfeições.

Figura 2 - Imagem de campanha ano 2011

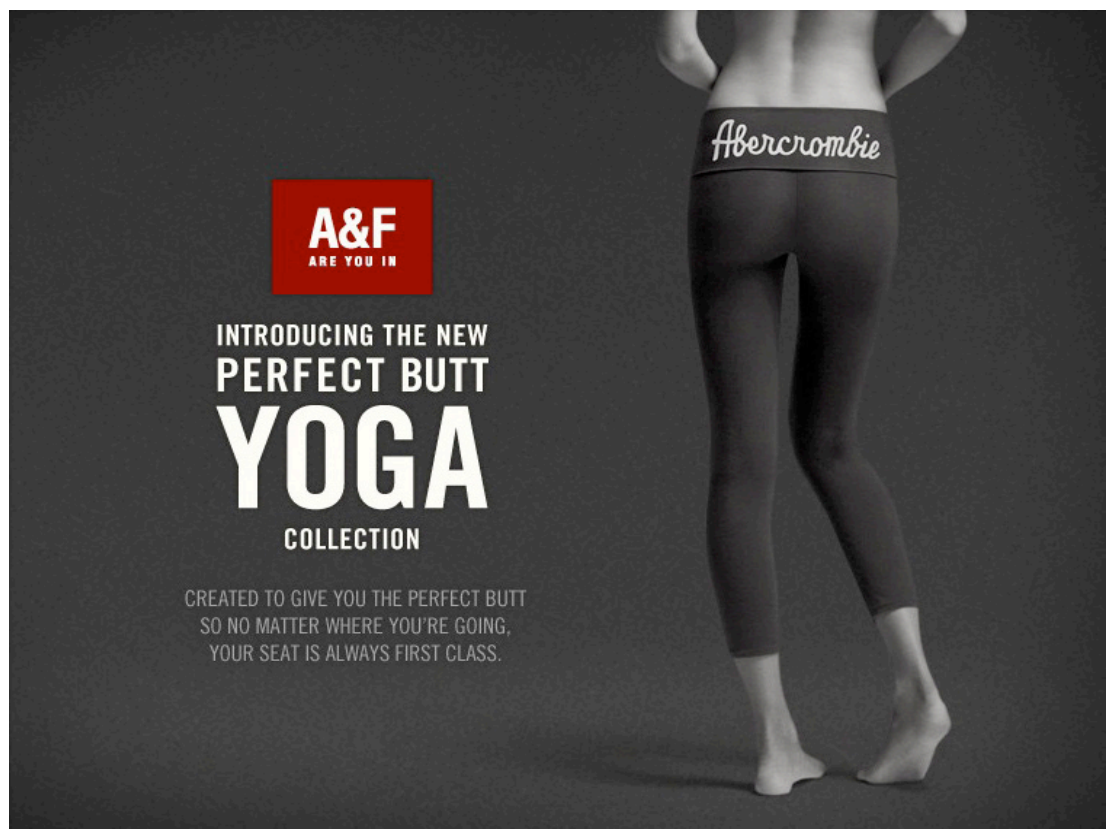

Fonte: Website Blisstree, setembro de 2011

A segunda imagem refere-se a divulgação de um modelo de calça específico para a prática de yoga. Além de apresentar um corpo extremamente 
magro, o anúncio faz uma falsa promessa de que a calça dará a aparência de nádegas perfeitas para quem use a peça, através do texto presente na imagem, escrito em inglês: "Apresentando a nova coleção de yoga 'bumbum' perfeito. Criada para Ihe proporcionar o 'bumbum' perfeito então não importa onde você vá, seu assento é sempe de primeira classe".

Figura 3 - Imagem da campanha Verão/2011

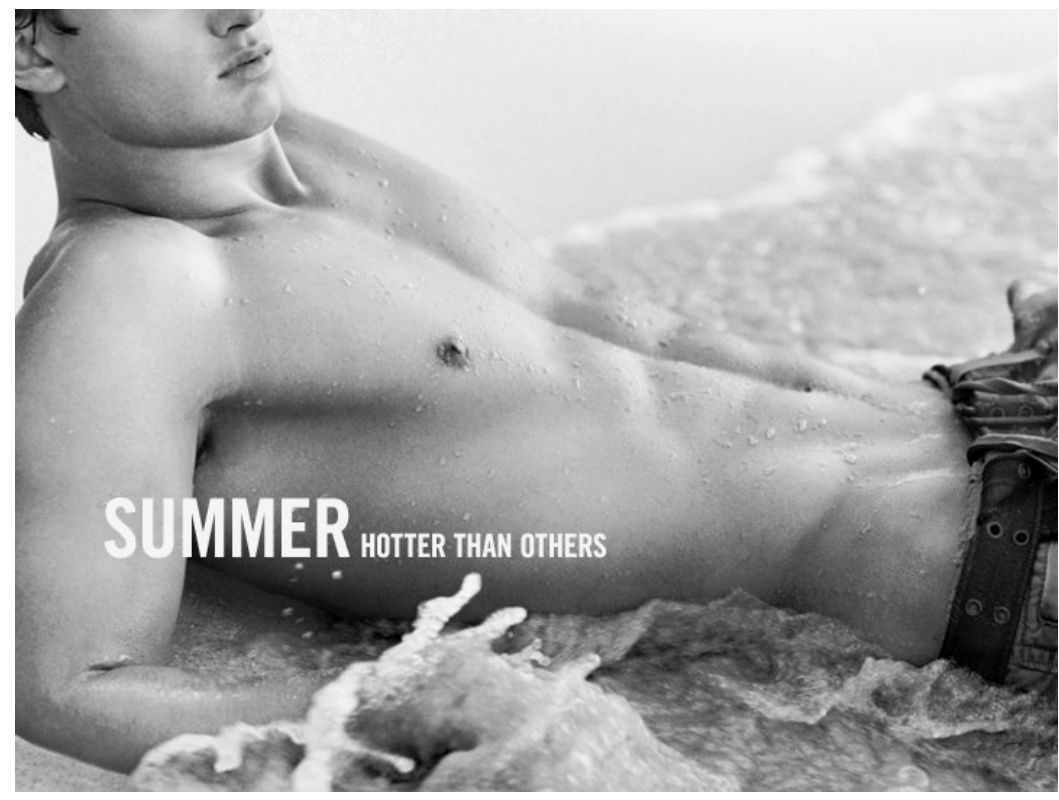

Fonte: Website Gotta Quirk, abril de 2011

A terceira imagem apresenta um rapaz com um corpo extremamente definido - que é o perfil de corpo masculino de todos os anúncios da marca - assim como dos próprios vendedores das lojas, que circulam sem camisa e são chamados de "modelos". A mensagem do anúncio tem duplo sentido e refere-se tanto ao verão (summer), como a pessoa que usa a roupa da marca através do termo "hotter" ( traduzido para o português como "mais quente", na língua inglesa pode também ser entendido como "mais atraente"). Assim, a promessa é de que quem usar a roupa, se tornará mais atraente do que os outros. Na imagem, a peça de roupa da marca - a calça jeans - praticamente não aparece no anúncio, evidenciando o corpo (magro e perfeito) e o apelo sexual da imagem.

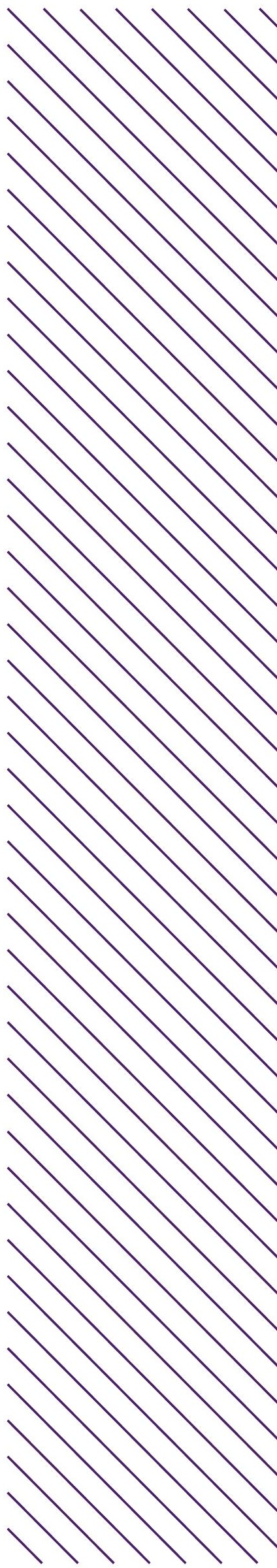


Figura 4 - Imagem de campanha ano desconhecido

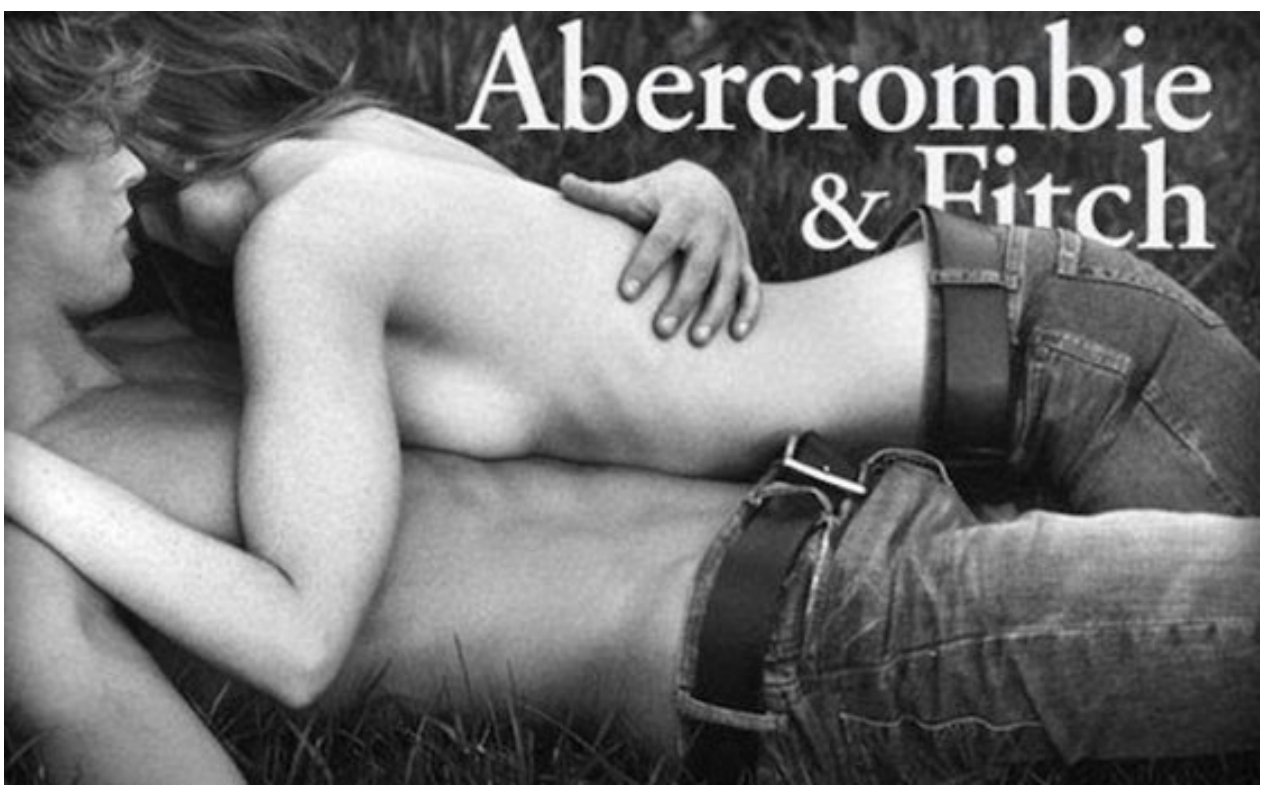

Fonte: Website Ethics In The News, setembro de 2013

Na quarta imagem, além do forte conteúdo sexual, pela posição dos corpos dos modelos e pela nudez, a magreza da modelo feminina chama atenção mostrando costelas aparentes. O apelo sexual mais uma vez é utilizado para atingir o público jovem.

De acordo com a porta-voz da empresa, Iska Hain, o público-alvo da marca são jovens bonitos e de físico atlético que estejam cursando o ensino médio ou a faculdade. E de fato eles têm conseguido atingir esse público pois, de acordo com a matéria públicada no site da revista Isto é dinheiro em fevereiro de 2011, a marca é uma das preferidas dos adolescentes de classes econômicas mais altas (BORIN, 2011).

As campanhas publicitárias da marca já geraram muita polêmica, e a publicação de uma revista trimestral contendo fotos de jovens em poses sensuais e muita nudez, foi considera como "soft porn" por grupos ativistas em prol da família nos E.U.A. Esses grupos incitaram boicotes a marca, levando a descontinuação da revista em 2003 que, no entanto, voltou a ser publicada em 2010 (LUTZ, 2013).

Utilizando-se de estratégias de marketing como essas - anúncios que cultuam corpos magros e torneados e de forte apelo sexual, exclusão de jovens acima do peso limitando os tamanhos das roupas a manequins pequenos - a marca, que atinge uma grande quantidade de jovens pelo mundo, acaba por criar mais insatisfações com a auto-imagem, prejudicando o processo de formação de identidade desses adolescentes. 


\section{PESQUISA DE CAMPO}

Com o intuito de constatar a visão dos jovens sobre o próprio consumo de moda, um questionário de 19 questões foi aplicado online em grupos de redes sociais. Integrando os dados coletados com as estratégias de marketing percebidas na revisão bibliográfica e os pontos destacados nas análises das imagens publicitárias, pretendeu-se identificar a visão do adolescente a respeito de seus hábitos de consumo.

\section{ANÁLISE DOS DADOS E DISCUSSÃO}

A partir do questionário aplicado no período de 21 de julho de 2014 a 28 de agosto de 2014, em jovens de 12 a 18 anos, a importância da roupa como forma de expressão de uma identidade foi corroborada.

Tabela 1 - Expressão da personalidade através da forma de vestir-se

\begin{tabular}{l|cc}
\hline \multicolumn{1}{c|}{ Sexo } & Sim & Não \\
\hline Feminino & 11 & 1 \\
Masculino & 5 & 3 \\
\hline Total & 16 & 4 \\
\hline
\end{tabular}

Fonte: elaborado pelos autores

A principal queixa a respeito do vestuário dedicado ao público adolescente foi a pouca oferta de roupas que se adequem ao corpo desses jovens, que encontram-se em uma fase de constantes mudanças corporais, o que talvez seja o motivo desse apontamento.

A maioria dos jovens pede opinião aos pais no momento da compra de artigos de vestuário, fato que pode ser relacionado a dependência financeira - e também emocional - em relação aos pais, de jovens nessa faixa etária. Entre as marcas de vestuário preferidas desses adolescentes, apareceram com mais frequência marcas de fast-fashion, em especial a marca Zara.

$\mathrm{Na}$ questão referente a auto-imagem, mais da metade dos jovens apresentaram alguma insatisfação com o próprio corpo.

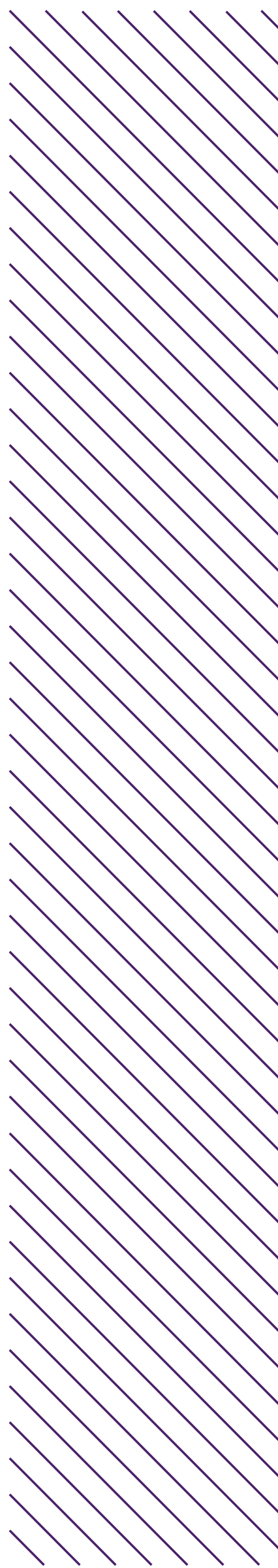


Tabela 2 - Opinião a respeito da própria aparência física

\begin{tabular}{l|ll}
\hline & Respostas & Porcentagem \\
\hline Me acho uma pessoa bonita. & 8 & $40 \%$ \\
$\begin{array}{l}\text { Me sinto bem, mas gostaria de modificar algumas } \\
\text { coisas (peso, altura, cabelo). }\end{array}$ & 11 & $55 \%$ \\
Estou muito insatisfeito com minha aparência. & 1 & $5 \%$ \\
\hline Total & 20 & $100 \%$ \\
\hline
\end{tabular}

Fonte: o próprio autor

Apesar da maioria dos adolescentes que responderam o questionário terem alegado indiferença a aparência dos jovens das campanhas publicitárias voltadas para eles, a maior parte desses adolescentes também acredita que 0 tipo fisico predominante nessas campanhas é muito distante da realidade.

Tabela 3 - Opinião a respeito do tipo físico apresentado em campanhas publicitárias

\begin{tabular}{l|lc}
\hline & Respostas & Porcentagem \\
\hline $\begin{array}{l}\text { Acho que adolescentes com essa aparência física só } \\
\text { existem nessas propagandas. }\end{array}$ & 4 & $20 \%$ \\
$\begin{array}{l}\text { Conheço poucas pessoas que têm a mesma aparência } \\
\text { física desses modelos. }\end{array}$ & 11 & $55 \%$ \\
Sim, eles se parecem com pessoas que eu conheço. & 5 & $25 \%$ \\
\hline Total & 20 & $100 \%$ \\
\hline
\end{tabular}

Fonte: o próprio autor

Através dos dados coletados com a pesquisa, podemos apontar a moda como um fator positivo na construção de identidade do jovem, já que ela é uma importante ferramenta utilizada pelo adolescente para expressão dessa identidade. De acordo com Oliveira (2013), ao adotar um estilo próprio, o indivíduo tenta afirmar sua identidade, tenta tornar-se único através de sua forma de vestir-se.

Contudo, entre as estratégias do marketing de moda para adolescentes, a utilização do mesmo estereótipo de jovem (garotas extremamente magras e jovens musculosos) em campanhas publicitárias, podem ser a causa da insatisfação dos adolescentes em relação a própria imagem, como foi visto na pesquisa. Para Tosatti, Peres e Preissler (2007), o corpo ideal apresentado pela mídia influencia mulheres - em especial, adolescentes - a sentirem-se insatisfeitas com o próprio corpo, levando-as a apelarem para dietas restritivas e exercícios físicos extenuantes, tentando transformar seus corpos em "ideais".

Como alternativa a essa estratégia, poderíamos sugerir a variação de 
biotipos em campanhas publicitárias adolescentes, para que as mesmas contribuam para uma melhor aceitação da auto-imagem do jovem e se aproximem da realidade dele, pois na pesquisa, os adolescentes apontaram grande distanciamento do tipo físico apresentado em campanhas publicitárias.

\section{CONCLUSÃO}

O papel da moda na formação de identidade, como já foi dito por diversos autores, é de grande relevância. Ela possibilita a singularização do indivíduo, permitindo a expressão de sua essência através de sua forma de vestir-se. A roupa, para quem a veste, contêm simbologias que representam, além da aparência física, um estado de espírito e a possibilidade de representar papéis diversos na sociedade.

No entanto, no período da adolescência, onde a busca por uma identidade é mais intensa, o jovem tem urgência em ser aceito e tenta estar de acordo com o "padrão ideal de beleza" vínculado pela mídia. As campanhas publicitárias - uma das estratégias do marketing - de moda adolescente, tem reforçado a existência dessa imagem ideal, o que contribue para uma não aceitação da auto-imagem, levando até a transtornos alimentares.

Excluir a existência de belezas e biotipos diferentes é um erro grave cometido por essas campanhas, que ao invés de se aproximarem do seu públicoalvo - os adolescentes - se distanciam dele. Porém entendemos que, excluir para tornar o produto único, desejável, dando a entender que ele é direcionado somente a um público seleto, também é uma estratégia de marketing.

A moda contribue sim, de forma positiva, na formação de identidade do adolescente. Mas a forma como ela é apresentada, oferecida a esse jovem, é em alguns casos, através de vias nocivas ao seu desenvolvimento. É importante todavia, ressaltar que essa padronização de um ideal de beleza, não é exclusividade da publicidade de moda, ela existe e é aceita em vários âmbitos da sociedade contemporânea.

\section{REFERÊNCIAS:}

ABERASTURY, Arminda; KNOBEL, Mauricio. Adolescência normal. Tradução de Suzana Maria Garagoray Ballve. Porto Alegre. Artes Médicas, 1981. 92 p. Tradução de: La adolescencia normal.

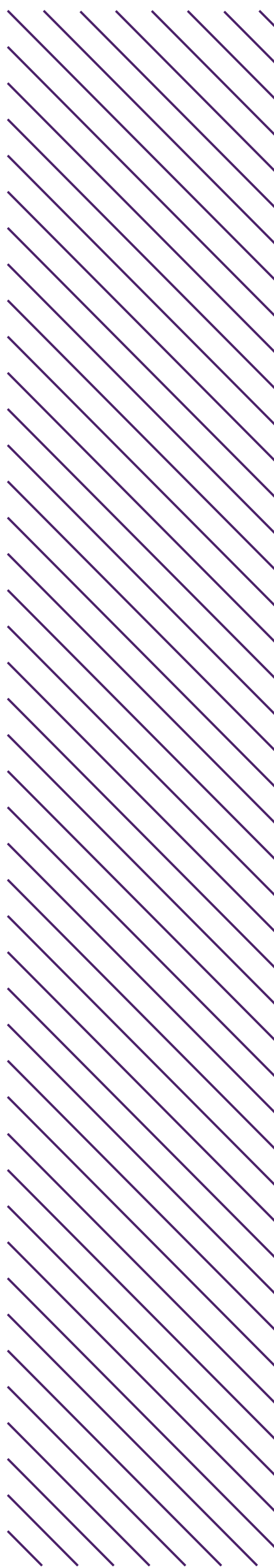


LTC, 1981.

BAUDRILLARD, Jean. A sociedade de consumoTradução por Artur Morão. Lisboa: Edições 70, 2010.

BAUDRILLARD, Jean. Simulacros e Simulação. Tradução de Maria João da Costa Pereira. Lisboa: Relógio d Água, 1991.

BENEDETTI, Francisco Carlos; NICOLETTI, Kátia Eliana da Silva. Estatística e moda adolescente: possibilidades por meio de análise fatorial e pesquisa de marketing. Faculdade de Tecnologia de Indaiatuba (FATEC-ID) 2010. Disponível em: <http://fatecindaiatuba.edu.br/reverte/index.php/revista/ article/view/46>. Acesso em: 24/06/2014

BORIN, Suzana. A febre da Abercrombie. Istoé Dinheiro. 11 fev. 2011. Seção Estilo. Disponível em: <http://www.istoedinheiro.com.br/ noticias/estilo/20110211/febre-abercrombie/58512.shtml>. Acesso em: 21/08/2014

BURROWES, Patrícia. Viagem ao território da publicidade. Comunicação, mídia e consumo, São Paulo, v. 2, n. 5, nov. 2005.

CANO, Maria Aparecida Tedeschi. et al. Auto-imagem na adolescência. Revista Eletrônica de Enfermagem, Goiânia, v. 1, n. 1, Out./Dez. 1999. Disponível em <http://h200137217135.ufg.br/index.php/fen/article/ view/668/734>. Acesso em: 21/08/2014

CASTRO, Geórgia Cardoso de; ALMEIDA, Ana Júlia Melo. A moda e a construção da identidade. In: Coloquio de Moda, 7., 2011, Anais do $7^{\circ}$ Colóquio de Moda.

CNN Wire Staff. Forever 21 asked about maternity line. Disponível em <http://edition.cnn.com/2010/LIVING/07/19/maternity.forever.21/>. Acesso em: 15/04/2014

CUNHA, Caroline de Souza Dutra da. Espelhos de Papel: Representações de uma sociedade em catálogos de moda (1998-2005). 2005. 59 fls. Monografia (Bacharelado em História) - Universidade do Estado de Santa Catarina, Centro de Ciências da Educação, Florianópolis, 2005. Disponível em: <http://www.pergamumweb.udesc.br/dadosbu/000000/000000000000/00000076.pdf>. Acesso em: 19/08/2014

DE SÃO PAULO, F. Popular entre adolescentes, Snapchat serve para marketing; veja como [Internet]. Classificados - Folha. 2015 Disponível 
em: http://classificados.folha.uol.com.br/negocios/2013/12/1388452popular-entre-adolescentes-snapchat-serve-para-marketing-vejacomo.shtml>. Acesso em: 15/04/2014

EHRENBERG, Karla Caldas. O consumo simbólico e a vida cotidiana. In: Conferência Brasileira de Comunicação com o Mercado, 2., 2012, Anais do II E-COM. Disponível em: <http://www2.metodista.br/unesco/1_ Ecom\%202012/E-book\%20\%20ECOM\%202012.pdf>. Acesso em: $18 / 07 / 2014$

EMBACHER, Airton. Moda e identidade: a construção de um estilo próprio. São Paulo: Anhembi Morumbi, 1999

GADE, Christiane. Psicologia do consumidor e da propaganda. São Paulo: Epu, 1998.

GERHARDT, Tatiana Engel; SILVEIRA, Denise Tolfo. Métodos de Pesquisa. 1. ed. Porto Alegre: Editora da UFRGS, 2009.

GIDDENS, Anthony. Modernidade e Identidade. Rio de Janeiro: Jorge Zahar, 2002. 233 p.

HEINZELMANN, Fernanda Lyrio; STREY, Marlene Neves. Meninas de Capricho, mulheres de Vogue: Imprensa feminina e a invenção da Adolescência eternal. In: Coloquio de Moda, 6., 2010, Anais do $6^{\circ}$ Colóquio de Moda.

LUTZ, Ashley. 13 reasons why people hate Abercrombie \& Fitch. 2013. Disponível em: <http://www.businessinsider.com/abercrombie-and-fitchworst-controversies-2013-8?op=1>. Acesso em: 19/07/2014

MIRANDA, Ana Paula de. Consumo de Moda: A relação pessoa-objeto. São Paulo: Estação das letras e cores, 2008.

MOURA, Tiago Bastos de. et al. Uma análise de concepções sobre a criança e a inserção da infância no consumismo. Psicol. cienc. prof., Brasília, v. 33, n. 2, 2013.

NASSIF, Maria de Fátima. Contra os abusos de uso da imagem da mulher, do homem, da criança e do adolescente na publicidade. In: Seminário preparatório para a conferência nacional de comunicação: contribuições da psicologia, 2009, Brasília. Disponível em: <http://site. cfp.org.br/wp-content/uploads/2009/07/Fatima_Nassif_-_Contra_os_ abusos_de_uso_da_imagem_da_mulher.pdf $>$. Acesso em: 22/05/2014

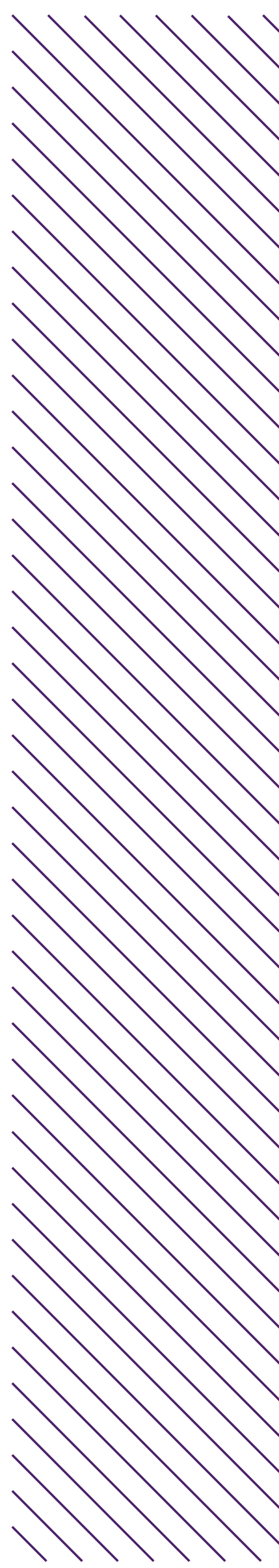


OLIVEIRA, Rafael Studart de. 0 poder de persuasão da publicidade contemporânea. 2009. 53 fls. Monografia (Bacharelado - Comunicação Social - Habilitação em Publicidade e Propaganda), Faculdade 7 de Setembro, Fortaleza, 2013. Disponível em: <http://www.fa7.edu.br/ recursos/imagens/File/publicidade/monografia/2009/rafael\%20studart. pdf>. Acesso em: 28/07/2014

OLIVEIRA, Talita Souza de. Moda: Um fator social. 2013. 126 fls. Dissertação (Mestrado - Ciência Têxtil e Moda), Universidade de São Paulo, Escola de Artes, Ciências e Humanidades, São Paulo, 2013.

PANDJIARJIAN, Paulo. A força do consumo adolescente. 2008. Disponível em: <http://www.portaleducacao.com.br/administracao/artigos/4590/aforca-do-consumo-adolescente>. Acesso em: 17/03/2014

PEREIRA, Adriano. et al. A Influência da mídia na vida dos adolescentes. Relações entre estética, consumismo e as psicopatologias. EFDeportes. com, Revista Digital. Buenos Aires, Ano 15, No 149, Outubro de 2010. Disponível em <http://www.efdeportes.com/efd149/a-influencia-damidia-na-vida-dos-adolescentes.htm>. Acesso em: 10/03/2014

PORTUGAL, Mirela. As marcas preferidas das mulheres da geração Y. Pesquisa do Goldman Sachs e da revista Teen Vogue aponta as queridinhas das consumidoras millenials. Exame.com. 03 out. 2013. Seção Marketing. Disponível em <http://exame.abril.com.br/marketing/ noticias/as-50-marcas-preferidas-das-mulheres-da-geracao-y\#25>. Acesso em: 15/04/2014

RIBEIRO, Paulo César Pinho. 0 adolescente e os consumos. Adolesc Saúde. 2005;2(3):21-24. Disponível em: <http://www. adolescenciaesaude.com/detalhe_artigo.asp?id=163>. Acesso em: $25 / 02 / 2014$

SCHIFFMAN, Leon. G; KANUK, Leslie Lazar. Comportamento do consumidor. 6. Ed. Rio de Janeiro: LTC, 2000.

SOLOMON, Michael R. Comportamento Do Consumidor Comprando, Possuindo e Sendo. Porto Alegre: Editora Bookman. 2006.

SOUZA, Luiz Carlos Carneiro de Faria e. Educação e Publicidade. São Paulo Perspec., São Paulo, v. 14, n. 2, Abr./Jun. 2000.

SOUZA, Valdete Vazzoler de; CUSTÓDIO, José de Arimathéia Cordeiro. Fotografia: meio e linguagem dentro da moda. Discursos fotográficos, 
Londrina, v. 1, 2005.

TOSATTI, Abykeyla Mellisse; PERES, Luciana; PREISSLER, Helena. Imagem corporal e as influências para os transtornos alimentares nas adolescentes jovens. Revista Brasileira de Obesidade, Nutrição e Emagrecimento, São Paulo, v. 1, n.4, Jul./Ago. 2007. Disponível em: <http://www.rbone.com.br/index.php/rbone/article/viewFile/36/34>. Acesso em: 14/06/2014

VERONESI, Luiza Belloni; Anti-"gordinhas", Abercrombie \& Fitch deixa de fabricar tamanhos G e GG. InfoMoney, \{S. I.\}, 10 maio 2013. Seção Minhas Finanças. Disponível em: <http://www.infomoney.com. $\mathrm{br} / \mathrm{minhas}$-financas/planos-saude/noticia/2770525/anti-gordinhasabercrombie-fitch-deixa-fabricar-tamanhos>. Acesso em: 15/04/2014 